\title{
STRES KERJA, KOMUNIKASI DAN LINGKUNGAN KERJA TERHADAP KINERJA KARYAWAN PT INDO PRIMA NUSANTARA
}

\author{
WORK STRESS, COMMUNICATION, AND WORK ENVIRONMENT ON \\ EMPLOYEE PERFORMANCE OF PT INDO PRIMA NUSANTARA
}

\author{
Cindy $^{1}$, Purnama Yanti Purba ${ }^{2}$, Henry Christian Wijaya ${ }^{3}$, Tommy Anggara ${ }^{4}$ \\ Universitas Prima Indonesia ${ }^{1,2,3,4}$ \\ cindykwok32@gmail.com ${ }^{1}$
}

\begin{abstract}
The business of making goods, the business of repairing goods, to the electronic and electrical credit businesses are found all around us. This study aims to determine and analyze the effect of work stress, communication, and work environment on employee performance. The phenomenon of increased public demand for electronic and electrical goods, increased work stress, ineffective communication, and an uncomfortable working environment underlie this research. The research method used is a quantitative approach, the type of research is quantitative descriptive, and the nature of this study is descriptive explanatory. The data analysis method used is multiple linear regression analysis. The sampling technique uses the saturation sampling method. The sample in this study was 80 employees. The results showed work stress, communication, and work environment had a positive and significant effect on employee performance. This means that the lower the work stress, the better the communication and work environment will be able to improve employee performance.
\end{abstract}

Keywords: Job Stress, Communication, Work Environment, Employee Performance

\begin{abstract}
ABSTRAK
Bisnis pembuatan barang, bisnis jasa reparasi barang, sampai bisnis kredit elektronik dan elektrik banyak ditemukan di sekitar kita. Penelitian ini bertujuan untuk mengetahui dan menganalisa pengaruh stres kerja, komunikasi, dan lingkungan kerja terhadap kinerja karyawan. Fenomena permintaan masyarakat yang meningkat terhadap barangbarang elektronik dan elektrik, peningkatan stres kerja, komunikasi yang kurang efektif, dan lingkungan kerja yang kurang nyaman melatarbelakangi penelitian ini. Metode penelitian yang digunakan adalah pendekatan kuantitatif, jenis penelitian ini deskriptif kuantitatif, dan sifat penelitian ini adalah deskriptif eksplanatory. Metode analisis data yang digunakan adalah analisis regresi linear berganda. Teknik penentuan sampel mengunakan metode sampling jenuh. Sampel dalam penelitian adalah 80 karyawan. Hasil penelitian menunjukkan stres kerja, komunikasi, dan lingkungan kerja berpengaruh positif dan signifikan terhadap kinerja karyawan. Hal ini berarti semakin rendah stress kerja, semakin baik komunikadi dan lingkungan kerja maka akan mampu meningkatkan kinerja karyawan.
\end{abstract}

Kata Kunci : Stres Kerja, Komunikasi, Lingkungan Kerja, Kinerja Karyawan 


\section{PENDAHULUAN}

$\begin{gathered}\text { Dewasa } \\ \text { masyarakatakan }\end{gathered}$
barang-barang
elektronik dan elektrik semakin meningkat. Hal ini menyebabkan bisnis elektronik saat ini banyak ditemukan di berbagai tempat. Dari mulai bisnis pembuatan barang, bisnis jasa reparasi barang, sampai bisnis kredit elektronik dan elektrik banyak ditemukan di sekitar kita. Daya beli masyarakat terhadap barang elektronik dan elektrik kini menjadi pesat contohnya adalah pembelian produk seperti lampu, televisi, radio player, DVD player, hingga perabot rumah tangga seperti lampu meja, kipas angin, senter, cooking pot, dan slow cooker. Semakin berkembang dan bertambahnya pelaku bisnis di bidang ini, maka semakin membuat para pelaku bisnis barang elektronik ditantang untuk dapat menciptakan diferensiasi produk yang unik dan menciptakan postioning yang jelas sehingga konsumen dapat membedakan dengan para pesaingnya. Kondisi pasar yang kompetitif dan dinamis akan mengakibatkan setiap perusahaan harus selalu mengamati persaingan dalam lingkungan bisnisnya.

Dalam menghadapi lingkungan persaingan yang semakin kuat dan ketat, setiap perusahaan dituntut harus mampu mengoptimalkan sumber daya ekonominya guna meningkatkan daya saing produknya di pasar, serta mampu meramu serangkaian strategi pemasaran yang efektif dan selalu mengembangkan strategi pemasaran tersebut secara terusmenerus serta berkelanjutan. Hal ini dilakukan sebagai upaya untuk meraih keunggulan kompetitif terhadap para perusahaan pesaing.

Daya saing di bidang elektronik dan elektrik yang cukup ketat dan tinggi perlu didukungnya kinerja yang optimal dari para karyawan di dalam suatu perusahaan. Kinerja karyawan adalah hasil kerja karyawan dilihat pada aspek kualitas, kuantitas waktu kerja dan kerja sama untuk mencapai tujuan yang sudah ditetapkan oleh organisasi (Lolowang et al., 2016). Beberapa hal yang dapat mempengaruhi kinerja karyawan yaitu stres kerja, komunikasi, dan lingkungan kerja

PT Indo Prima Nusantara merupakan sebuah perusahaan yang bergerak di bidang distributor elektrik dan elektronik seperti kipas angin, lampu, senter, electric cup, kettle, dan sebagainya yang bermerek Yundai, Kawachi dan Steele. Berdasarkan hasil wawancara awal bahwa terjadinya penurunan kinerja karyawan yang terlihat dari tidak tercapainya target perusahaan. Pada perusahaan PT Indo Prima Nusantara terindikasi bahwa karyawan yang mengalami stres dalam bekerja yang mengakibatkan jumlah karyawan memilih keluar dari perusahaan.

Komunikasi di PT Indo Prima Nusantara juga terindikasi tidak berjalan dengan baik. Terjadinya kesalahan dalam bekerja yang disebabkan oleh kurang jelasnya dalam berkomunikasi baik antara karyawan maupun dengan atasan. Hal ini disebabkan oleh kesalahan menginformasikan kode barang, harga yang berbeda, alamat baru dan kesalahan kegiatan promosi produk sehingga, terjadi kurangnya kejelasan dalam komunikasi, kurangnya beberapa komunikasi karyawan dikarenakan konflik pribadi dan perlengkapan komunikasi yang kurang mendukung cepatnya proses komunikasi.

Lingkungan kerja di PT Indo Prima Nusantara terindikasi kurang nyaman. Dimana banyaknya keluhan terjadi pada divisi marketing, gudang, HRD, keuangan dan penjualan mengenai AC tidak sejuk, remot AC rusak, konfik dengan rekan kerja, 
ruangan yang sempit, ruangan yang panas untuk gudang, kebersihan belum terjaga, kamar mandi kotor, ruangan kerja yang banyak sampah, sistem manajemen yang menyulitkan dalam permintaan cuti, perlengkapan yang kurang memadai printer yang sering error dan konflik dengan rekan kerja satu divisisehingga menyebabkan rusaknya konsentrasi karyawan dalam bekerja serta hubungan yang kurang harmonis antara karyawan senior dengan karyawan baru dimana karyawan yang lebih mempunyai masa kerja yang lama tidak ingin memberikan penjelasan atau bantuan terhadap penyelesaian pekerjaan karyawan baru sehingga terkadang memicu timbulnya konflik.

Pengelolaan stres memerlukan pemahaman tentang stress, faktor-faktor yang mempengaruhi serta konsekuensi dari stres itu sendiri. Pengelolaan stress dapat dilakukan dengan menggunakan pendekatan-pendekatan tertentu yang mengatasi stress (Tolo et al., 2016). Pada akhirnya pengelolaan stres yang dilakukan oleh organisasi dapat meningkatkan kinerja organisasi secara keseluruhan. Hasil penelitian ini sejalan dengan hasil penelitian Tjokro (2015) bahwa stres kerja berpengaruh terhadap kinerja karyawan.

Komunikasi organisasi yang semakin baik akan mengurangi stress akibat ambiguitas pekerjaan (Sumaki 2015). Demikian pula, program perencanaan kinerja seperti MBO dapat memaparkan dengan jelas tanggung jawab pekerjaan, menyediakan sasaran kinerja yang terarah dan mengurangi ambiguitas melalui umpan balik.Hasil penelitian ini sejalan dengan hasil penelitian Ardiansyah (2016) bahwa komunikasi berpengaruh positif dan signifikan terhadap kinerja karyawan.

$$
\text { Kinerja karyawan dapat }
$$
dipengaruhi oleh berbagai faktor baik yang berhubungan dengan manusia maupun yang berhubungan dengan lingkungan tempatnya bekerja, baik dari internal perusahaan maupun eksternal perusahaan (kebijakan pemerintah) (Yudistiro 2015). Hasil penelitian ini sejalan dengan hasil penelitian Sidanti (2015) bahwa lingkungan kerja berpengaruh positif dan signifikan terhadap kinerja karyawan.

Untuk itu bagi menjawab masalah dan fenomena kinerja yang ada pada perusahaan ini, peneliti mencoba menelaah secara teoretis maupun hasil penelitian yang relevan sehingga ditemukannya bahwa faktor stress kerja, komunikasi dan lingkungan kerja memiliki peran penting dalam meningkatkan kinerja karyawan.

\section{METODE PENELITIAN}

Pendekatan dalam penelitian ini adalah pendekatan kuantitatif. Dalam penelitian ini, peneliti menggunakan metode penelitian deskriptif kuantitatif. Sifat penelitian yang digunakan adalah deskriptif explanatory. Sampel berjumlah 80 karyawan. Teknik pengambilan sampel adalah metode sampling jenuh. Dalam penelitian ini, pengumpulan data terkait permasalahan yang diteliti oleh peneliti dilakukan dengan cara kuesioner, wawancara dan studi dokumentasi. Sumber data adalah data primer dan sekunder. Metode analisis data yang digunakan adalah analisis regresi linear berganda.

\section{HASIL DAN PEMBAHASAN}

PT Indo Prima Nusantara adalah perusahaan Distributor Elektrik khususnya lampu merek KAWACHI di Medan, yang telah berdiri sejak lebih dari 10 tahun dan memiliki banyak cabang di luar Sumatera.PT Indo Prima Nusantara dinilai sebagai perusahaan yang mampu membangun dan mengelola reputasi perusahaan yang 
sangat baik. "Kinerja perusahaan akan kualitas produk dan inovatif yang diberikan, pengelolaan perusahaan yang baik, kepedulian terhadap isu sosial dan lingkungan, serta lingkungan kerja yang kondusif mampu membawa PT Indo Prima Nusantara sebagai salah satu perusahaan yang memiliki reputasi terbaik di Indonesia.

\section{Uji Validitas}

Tabel 1 Hasil Uji Validitas

\begin{tabular}{|c|c|c|c|c|c|c|c|c|c|c|}
\hline \multirow[t]{2}{*}{ No } & \multicolumn{2}{|c|}{ Stres Kerja } & \multicolumn{2}{|c|}{$\begin{array}{c}\text { Komunikasi } \\
\text { Kerja }\end{array}$} & \multicolumn{2}{|c|}{$\begin{array}{c}\text { Lingkungan } \\
\text { Kerja }\end{array}$} & \multicolumn{2}{|c|}{ Kinerja } & \multirow{2}{*}{ rtabel } & \multirow[t]{2}{*}{ Keterangar } \\
\hline & $r_{\text {hitung }}$ & Sig. & $r_{\text {hitung }}$ & Sig. & rhitung & Sig. & $r_{\text {hitung }}$ & Sig. & & \\
\hline 1 & 0.83 & 0,000 & 0.558 & 0,001 & 0.462 & 0,010 & 0.434 & 0,017 & 0,361 & Valid \\
\hline 2 & 0.86 & 0,000 & 0.668 & 0,000 & 0.453 & 0,0012 & 0.634 & 0,000 & 0,361 & Valid \\
\hline 3 & 0.799 & 0,000 & 0.67 & 0,000 & 0.55 & 0,002 & 0.678 & 0,000 & 0,361 & Valid \\
\hline 4 & 0.886 & 0,000 & 0.586 & 0,001 & 0.516 & 0.003 & 0.506 & 0.004 & 0,361 & Valid \\
\hline 5 & 0.785 & 0,000 & 0.4 & 0,029 & 0.504 & 0,005 & 0.762 & 0,000 & 0,361 & Valid \\
\hline 6 & 0.614 & 0,000 & 0.702 & 0,000 & 0.527 & 0,003 & 0.794 & 0,000 & 0,361 & Valid \\
\hline 7 & & & 0.764 & 0,000 & 0.693 & 0,000 & 0.778 & 0,000 & 0,361 & Valid \\
\hline 8 & & & 0.661 & 0,000 & 0.513 & 0,004 & 0.846 & 0,000 & 0,361 & Valid \\
\hline 9 & & & 0.597 & 0,001 & & & 0.831 & 0,000 & 0,361 & Valid \\
\hline 10 & & & 0.438 & 0,015 & & & 0.497 & 0,005 & 0,361 & Valid \\
\hline 11 & & & & & & & 0.466 & 0,001 & 0,361 & Valid \\
\hline 12 & & & & & & & 0.474 & 0,014 & 0,361 & Valid \\
\hline
\end{tabular}

Sumber: Data primer yang diolah, 2019

Tabel 1 menunjukkan bahwa hasil pengujian instrumen dari variabel stress kerja, kompetensi, disiplin kerja dan kinerja karyawan memiliki nilai $r_{\text {hitung yang lebih besar dari } r_{\text {tabel }} \text { dan nilai }}$ sig.dibawah 0,05. Dengan demikian dapat disimpulkan bahwa seluruh instrumen pertanyaan dari variabel stress kerja, kompetensi, disiplin kerja dan kinerja karyawan yang digunakan adalah valid dan dapat digunakan dalam penelitian.

\section{Uji Reliabilitas}

Menurut Ghozali (2016:47), uji reliabilitas sebenarnya adalah alat untuk mengukur suatu kuesioner yang merupakan indikator dari variabel atau konstruk. Cronbach's alpha $<0.6=$ reliabilitas buruk.

1. Cronbach's alpha 0,6-0,79= reliabilitas diterima.

2. Cronbach's alpha $0,8=$ reliabilitas baik.

Tabel 2 Uji Reliabilitas

\begin{tabular}{clccc}
\hline No. & Variabel & Cronbach's Alpha & N of Items & Keterangan \\
\hline 1. & Stress Kerja $\left(\mathrm{X}_{1}\right)$ & 0,877 & 6 & Reliabel \\
\hline 2. & Komunikasi Kerja $\left(\mathrm{X}_{2}\right)$ & 0,805 & 10 & Reliabel \\
\hline 3. & Lingkungan Kerja $\left(\mathrm{X}_{3}\right)$ & 0,612 & 8 & Reliabel \\
\hline 4. & Kinerja Karyawan $(\mathrm{Y})$ & 0,835 & 12 & Reliabel \\
\hline
\end{tabular}

Sumber : Data primer yang diolah, 2019 
Tabel 2 dapat diketahui bahwa nilai Cronbach's Alpha dari seluruh variabel yang diujikan niainya sudah diatas 0,60 , maka dapat disimpulkan bahwa seluruh variabel yaitu komeptensi, disiplin, kepuasan kerja dan kinerja karyawan dalam penelitian ini lolos dalam uji reliabilitas dan dinyatakan reliabel.

\section{Statistik Deskriptif}

Berikut ini adalah statistik deskriptif dari jawaban minimum, maksimum, rata-rata dan standart deviasi para responden, yaitu :

Tabel 3 Statistik Deskriptif

\begin{tabular}{|c|c|c|c|c|c|}
\hline \multicolumn{6}{|c|}{ Descriptive Statistics } \\
\hline & $\mathrm{N}$ & Minimum & Maximum & Mean & Std. Deviation \\
\hline StressKerja & 80 & 10 & 30 & 16.75 & 4.788 \\
\hline KomunikasiKerja & 80 & 10 & 50 & 29.16 & 9.360 \\
\hline LingkunganKerja & 80 & 8 & 40 & 25.53 & 7.328 \\
\hline KinerjaKaryawan & 80 & 12 & 60 & 36.31 & 9.835 \\
\hline Valid N (listwise) & 80 & & & & \\
\hline
\end{tabular}

Sumber : Data primer yang diolah, 2019

Tabel 3 menunjukkan bahwa statistik deskriptif untuk variabel stress kerja mempunyai nilai minimum sebesar 10 dan nilai maksimum sebesar 30 dengan nomor responden 12,50 , nilai mean sebesar 16,75 dan standar deviasi sebesar 4,788. Statistik deskriptif untuk variabel komunikasi kerja mempunyai nilai minimum sebesar 10 dengan nomor responden 1, nilai maksimum sebesar 50 dengan nomor responden 2,3,4,8,9, nilai mean sebesar 29,16 dan standar deviasi sebesar 9,360.Statistik deskriptif untuk variabel lingkungan kerja mempunyai nilai minimum sebesar 8 dengan nomor responden 1,34,46,70, nilai maksimum sebesar 40 dengan nomor responden $2,3,4,5,12,13,14,74$, nilai mean sebesar 25,53 dan standar deviasi sebesar 7,328. Statistik deskriptif untuk variabel kinerja karyawan mempunyai nilai minimum sebesar 12 dengan nomor responden 1,79,80, nilai maksimum sebesar 60 dengan nomor responden 2,3, nilai mean sebesar 36,31 dan standar deviasi sebesar 9,835.

\section{Hasil Analisis Regresi Linear Berganda}

Model regresi yang digunakan adalah analisis regresi linear berganda sebagai berikut

Tabel 4 Hasil Analisis Regresi Linear Berganda

\begin{tabular}{|c|c|c|c|}
\hline \multirow[t]{2}{*}{ Model } & \multicolumn{3}{|c|}{ Unstandardized Standardized } \\
\hline & B & $\begin{array}{l}\text { Std. } \\
\text { Error }\end{array}$ & Beta \\
\hline (Constant) & 8.534 & 5.022 & \\
\hline stresskerja & .485 & .196 & .236 \\
\hline komunikasikerja & .222 & .106 & .212 \\
\hline lingkungankerja & .516 & .136 & .385 \\
\hline
\end{tabular}

Sumber : Data primer yang diolah, 2019

Kinerja Karyawan $=\mathbf{8 , 5 3 4}+\mathbf{0 , 4 8 5}$ $\mathrm{X}_{1}+0,222 \mathrm{X}_{2}+0,516 \mathrm{X}_{3}+\mathrm{e}$

Tabel 7 menunjukkan bahwa rumus analisis regresi linear di atas dapat dijelaskan jika stress kerja, komunikasi kerja dan lingkungan kerja tidak mengalami peningkatan atau konstan maka kinerja karyawan sebesar 8,534 satuan. Jika terjadi peningkatan sebesar 1 satuan untuk variabel 
independen stress kerja maka kinerja karyawan akan bertambah sebesar 0,485 satuan dengan anggapan variabel lainnya tetap. Jika terjadi peningkatan sebesar 1 satuan untuk variabel independen komunikasi kerja maka kinerja karyawan akan bertambah sebesar 0,222 satuan dengan anggapan variabel lainnya tetap. Jika terjadi peningkatan sebesar 1 satuan untuk variabel independen lingkungan kerja maka kinerja karyawan akan bertambah sebesar 0,222 satuan dengan anggapan variabel lainnya tetap.

\section{Koefisien Determinasi Hipotesis}

Koefisien determinasi dapat dilihat dari angka Adjusted $R$ Square

Tabel 5 Uji Koefisien Determinasi

\begin{tabular}{lcccc}
\hline \multicolumn{4}{c}{ Model Summary $^{\mathbf{b}}$} \\
\hline Model & $\mathrm{R}$ & $\mathrm{R}$ & $\begin{array}{c}\text { Adjusted } \\
\text { Square } \\
\text { R Square }\end{array}$ & $\begin{array}{c}\text { Std. Error } \\
\text { of the } \\
\text { Estimate }\end{array}$ \\
\hline 1 & $.560^{\text {a }}$ & .314 & .287 & 8.30724 \\
\hline Sumber :Data primer yang diolah, 2019
\end{tabular}

Tabel 5 menunjukkan bahwa nilai Adjusted RSquare sebesar 0,287. Hal ini berarti $28,7 \%$ kinerja karyawan yang dapat dijelaskan oleh stress kerja, komunikasi dan lingkungan kerja sedangkan sisanya sebesar 71,3\% dijelaskan oleh variabel lain, seperti promosi jabatan, gaji, analisa jabatan dan sebagainya.

\section{Pengujian Hipotesis Secara Simultan}

Tabel 6 Uji Simultan (Uji F)

\begin{tabular}{lllllll}
\hline \multicolumn{6}{c}{ ANOVA $^{\mathrm{a}}$} \\
\hline Model & $\begin{array}{c}\text { Sum of } \\
\text { Squares }\end{array}$ & df & $\begin{array}{c}\text { Mean } \\
\text { Square }\end{array}$ & F & Sig. \\
\hline \multirow{2}{*}{1} & Regression & 2396.408 & 3 & 798.803 & 11.575 & $.000^{\mathrm{b}}$ \\
\cline { 2 - 7 } & Residual & 5244.780 & 76 & 69.010 & & \\
\cline { 2 - 6 } & Total & 7641.188 & 79 & & & \\
\hline
\end{tabular}

Sumber : Data primer yang diolah, 2019
Tabel 6 menunjukkan bahwa derajat bebas $1\left(\mathrm{df}_{1}\right)=\mathrm{k}-1=4-1=3$, dan derajat bebas $2\left(\mathrm{df}_{2}\right)=\mathrm{n}-\mathrm{k}=80-4=$ 76 , dimana $\mathrm{n}=$ jumlah sampel, $\mathrm{k}=$ jumlah variabel, maka nilai $F$ tabel pada taraf kepercayaan signifikansi 0,05 adalah 2,72 hasil perhitungan SPSS di atas diperoleh nilai $F$ hitung sebesar 11,575> $\mathrm{F}$ tabel sebesar 2,72 dengan tingkat signifikansi 0,000 $<0,05$. Dapat disimpulkan bahwa $\mathrm{Ha}$ ditolak dan $\mathrm{H}_{0}$ diterima yaitu secara simultan stress kerja, komunikasi dan lingkungan kerja berpengaruh positif dan signifikan terhadap kinerja karyawan pada PT Indo Prima Nusantara (Perusahaan Distributor Elektrik/Elektronik Kawachi).

\section{Pengujian Hipotesis Secara Parsial}

Uji $t$ digunakan untuk mengetahui ada tidaknya hubungan atau pengaruh yang berarti (signifikan) antara variabel independen secara parsial terhadap variabel dependen.

Tabel 7 Uji Parsial (Uji t)

\begin{tabular}{llll}
\hline Model & $\mathrm{t}$ & Sig. \\
& & & \\
\hline \multirow{2}{*}{1 (Constant) } & 1.699 & .093 \\
\cline { 2 - 4 } & stresskerja & 2.467 & .016 \\
\cline { 2 - 4 } & Komunikasi kerja & 2.092 & .040 \\
\cline { 2 - 4 } & Lingkungan kerja & 3.793 & .000 \\
\hline
\end{tabular}

Sumber :Data primer yang diolah, 2019

Dengan demikian hasil dari Uji t dapat dijelaskan sebagai berikut hasil perhitungan hipotesis secara parsial diperoleh nilai thitungstres kerja sebesar $2,467>t_{\text {tabel }}$ sebesar 1,992 dan nilai signifikan $0,016<0,05$. Dapat disimpulkan bahwa Ho ditolak dan $\mathrm{H}_{\mathrm{a}}$ diterima yaitu secara parsial stress kerja berpengaruhpositif dan signifika nterhadap kinerja karyawan pada PT Indo Prima Nusantara (perusahaan distributor elektrik/elektronik Kawachi). Hasil uji hipotesis secara parsial 
diperoleh nilai thitung komunikasi kerja sebesar 2,092 $>\mathrm{t}_{\text {tabel }}$ sebesar 1,995 dan nilai signifikan $0,040<0,05$. Dapat disimpulkan bahwa Ho ditolak dan $\mathrm{H}_{\mathrm{a}}$ diterima yaitu secara parsial komunikasi kerja berpengaruhpositif dan signifikan terhadap kinerja karyawan pada PT Indo Prima Nusantara (perusahaan distributor elektrik/elektronik kawachi).Hasil uji hipotesis secara parsial diperoleh nilai thitung lingkungan kerja sebesar 3,793>t tabel sebesar 1,995 dan nilai signifikan $0,000<0,05$. Dapat disimpulkan bahwa Ho ditolak dan $\mathrm{H}_{\mathrm{a}}$ diterima yaitu secara parsial lingkungan kerja berpengaruhpositif dan signifikan terhadap kinerja karyawan pada PTIndo Prima Nusantara (perusahaan distributor elektrik/elektronik Kawachi).

\section{Pengaruh Stres terhadap Kinerja Karyawan}

Hasil perhitungan hipotesis pertama dapat disimpulkan bahwa stress kerja berpengaruhpositif dan signifikan secara parsial terhadap kinerja karyawan pada PT Indo Prima Nusantara (perusahaan distributor elektrik/elektronik Kawachi). Pengelolaan stres memerlukan pemahaman tentang stress, faktor-faktor yang mempengaruhi serta konsekuensi dari stres itu sendiri (Tolo et al., 2016). Pengelolaan stress dapat dilakukan dengan menggunakan pendekatanpendekatan tertentu yang mengatasi stres. Pada akhirnya pengelolaan stres yang dilakukan oleh organisasi dapat meningkatkan kinerja organisasi secara keseluruhan. Hasil penelitian ini sejalan dengan hasil penelitian Tjokro (2015) bahwa stres kerja berpengaruh terhadap kinerja karyawan.

\section{Pengaruh Komunikasi Kerja terhadap Kinerja Karyawan \\ Hasil perhitungan hipotesis \\ kedua disimpulkan bahwa hipotesis}

kedua diterima yang menyatakan komunikasi kerja berpengaruhpositif dan signifikan secara parsial terhadap kinerja karyawan pada PT Indo Prima Nusantara (Perusahaan Distributor Elektrik/Elektronik Kawachi). Hal ini mendukung hipotesis kedua. Komunikasi organisasi yang semakin baik akan mengurangi stress akibat ambiguitas pekerjaan (Sumaki 2015). Demikian pula, program perencanaan kinerja seperti MBO dapat memaparkan dengan jelas tanggung jawab pekerjaan, menyediakan sasaran kinerja yang terarah dan mengurangi ambiguitas melalui umpan balik.Hasil penelitian ini sejalan dengan hasil penelitian Ardiansyah (2016) bahwa komunikasi berpengaruh positif dan signifikan terhadap kinerja karyawan.

\section{Pengaruh Lingkungan Kerja terhadap Kinerja Karyawan \\ Hasil perhitungan hipotesis} ketiga dapat disimpulkan bahwa hipotesis ketiga diterima yaitu secara parsial lingkungan kerja berpengaruh positif dan signifikan secara parsial terhadap kinerja karyawan pada PT Indo Prima Nusantara (Perusahaan Distributor Elektrik/Elektronik Kawachi). Hal ini mendukung hipotesis ketiga. Kinerja karyawan dapat dipengaruhi oleh berbagai faktor baik yang berhubungan dengan manusia maupun yang berhubungan dengan lingkungan tempatnya bekerja, baik dari internal perusahaan maupun eksternal perusahaan (kebijakan pemerintah) (Yudistiro 2015). Hasil penelitian ini sejalan dengan hasil penelitian Sidanti (2015) bahwa lingkungan kerja berpengaruh positif dan signifikan terhadap kinerja karyawan . 
PENUTUP

Kesimpulan

Dari hasil penelitian dapat disimpulkan bahwa secara parsial stress kerja, komunikasi, dan lingkungan kerja berpengaruh positif dan signifikan terhadap kinerja karyawan pada PT Indo Prima Nusantara (Perusahaan Distributor Elektrik/Elektronik Kawachi) maka hasil penelitian mendukung hipotesis peneliti. Sementara itu secara simlultan stress kerja, komunikasi, dan lingkungan kerja berpengaruhpositif dan signifikan terhadap kinerja karyawan pada PT Indo Prima Nusantara (Perusahaan Distributor Elektrik/Elektronik Kawachi).

\section{Saran}

Bagi perusahaan, disarankan untuk menciptakan semangat kerja dengan pemberian penghargaan dan promosi jabatan secara berkala. Dalam hal komunikasi disarankan melakukan penambahan alat komunikasi yang lebih canggih sehingga memudahkaan karyawan dalam bekerja dan untuk menciptakan hubungan antara karyawan maka sebaiknya dilakukan gathering karyawan sehingga memicu rasa harmonis.

\section{DAFTAR PUSTAKA}

Ardiansyah, D., O. (2016). Pengaruh Komunikasi Terhadap Kinerja Karyawan Dengan Dimediasi Oleh Kepuasan Kerja (Studi Pada Bagian Produksi Pabrik Kertas PT. Setia Kawan Makmur Sejahtera Tulungagung). Jurnal Bisnis dan Manajemen, 3(1).

Lolowang, M., G., Adolfina, A., \& Lumintang, G. (2016). Pengaruh Pelatihan dan Pengembangan Sumber Daya Manusia terhadap
Kinerja Karyawan pada Pt. Berlian Kharisma Pasifik Manado. Jurnal EMBA: Jurnal Riset Ekonomi, Manajemen, Bisnis dan Akuntansi, 4(2).

Sidanti, H. (2015). pengaruh lingkungan kerja, disiplin kerja dan motivasi Kerja terhadap kinerja pegawai negeri sipil di Sekretariat DPRD kabupaten madiun. Jurnal Jibeka, 9(1), 44-53.

Sumaki, W. (2015). Pengaruh Disiplin Kerja, Budaya Organisasi, dan Komunikasi Terhadap Kinerja Karyawan PT. PLN (Persero) Wilayah Suluttenggo Area Manado. Jurnal Berkala Ilmiah Efisiensi, 15(5).

Tjokro, C., I. (2015). Pengaruh Konflik Peran Ganda dan Stress Kerja terhadap Kinerja Perawat Rumah Sakit Umum Dr. M. Haulussy Ambon. ARTHAVIDYA, 17(1).

Tolo, I., Sepang, J. L., \& Dotulong, L. O. (2016). Pengaruh Keterampilan Kerja Disiplin Kerja dan Lingkungan Kerja Terhadap Kinerja Pegawai Pada Dinas Pemuda dan Olahraga (DISPORA) Manado. Jurnal EMBA: Jurnal Riset Ekonomi, Manajemen, Bisnis dan Akuntansi, 4(3).

Yudistiro, I., A. (2015). Pengaruh Kecerdasan Emosional, Lingkungan Kerja dan Disiplin Terhadap Kinerja Guru dengan Komitmen Organisasi Sebagai Moderasi. Jurnal Sumber Daya Manusia, 9(1), 38-50. 